\title{
Endogenous Infection
}

National Cancer Institute

\section{Source}

National Cancer Institute. Endogenous Infection. NCI Thesaurus. Code C128367.

An infection caused by an infectious agent that is present on or in the host prior to the start of the infection. 